\title{
PATTERN OF CUTANEOUS MANIFESTATIONS OF DIABETES MELLITUS
}

KEY WORDS: Diabetes

Mellitus, Cutaneous

Manifestations.

\section{Dr. Satpal Yadav \\ Dr.Aman Goyal*}

Jr. Specialist Skin AndV.D., Govt. Rajiv Gandhi, General Hospital, Alwar

Asstt. Professor, Department of Dermatology, Venereology and Leprosy, Maharaja Agrasen Medical College, Agroha, Hisar, Haryana

*Corresponding Author

\section{Dr.Poonam Verma}

\section{Sr.Resident, Maharaja Agrasen Medical College, Agroha, Hisar, Haryana}

BACKGROUND: Diabetes is most common endocrine disorder with increasing prevalence worldwide. Every organs system is affected by it albeit at different pace. This study was carried out with the aim of studying cutaneous manifestation of diabetes mellitus.

METHODS- 200 cases of diabetes mellitus with cutaneous manifestations attending out patient department of dermatology were included in the study.

RESULTS - The common skin disorders were cutaneous infections (53.5\%), acanthosis nigricans (10.5\%), generalized pruritus (10.5\%), skintags $(9.5 \%)$.

CONCLUSION - most common dermatological manifestations were cutaneous infections.

\section{INTRODUCTION:}

Diabetes is characterized by state of chronic hyperglycemia due to absolute or relative insulin deficiency. This state of hyperglycemia affects various organs system including cardiovascular, renal, nervous system, eye and skin ${ }^{1}$. Skin manifestations in diabetes mellitus are common and expressed in numerous forms. According to various studies, $30-82 \%$ of persons with diabetes mellitus have some type of cutaneous involvement during the course of disease $\mathrm{e}^{2-3}$. In general, type two DM patients tend to develop more frequent cutaneous infections, whereas type one DM patients develop more autoimmune type of cutaneous lesions $\mathrm{s}^{4-5}$.

Hyperglycemia leads to nonenzymatic glycosylation (NEG) of various structural and regulatory proteins including collagen. NEG leads to formation of advanced glycosylation end products (AEG), which contribute to pathogenesis of disorders such as diabetic thick skin and limited joint mobility $(\mathrm{LJM})^{6}$. The etiopathogenesis of systemic and cutaneous infections which are a significant cause of morbidity and mortality in DM is linked to derangements in immuno regulatory mechanism like diminish chemotaxis, phagocytosis and reduced cell mediated immunity ${ }^{\text {. }}$. Metabolic abnormalities like hyperinsulinemia seen in early type $2 \mathrm{DM}$, by virtue of its action on insulin like growth factors - I (IGF-1) receptor appears to mediate abnormal epidermal proliferation and phenotype of acanthosis nigricans ${ }^{8}$. In insulin deficient diabetic patients abnormal Lipoprotein lipase (LPL) activity resulting in defective lipid processing and can lead to massive hypertriglyceridemia manifesting in skin as eruptive xanthomas. Macro and microangiopathy contribute significantly to the cutaneous complications of diabetes. In addition, a loss of cutaneous sensory innervations occurs with diabetes. All the above factors in combination and loss of neuroinflammatory cell signaling plays a casual role in non-healing, lower extremity ulcers'. Cutaneous lesions in diabetes may be classified into four major groups:

1. Skin disease with strong to week association with diabetes mellitus eg. necrobiosis lipoidica, diabetic dermopathy, diabetic thick skin, acanthosis nigricans, granuloma annulare, diabetic bullae, skin tags, yellow nails, xanthomas, rubeosis faciae, xerosis etc.

2. Cutaneous infections - eg. fungal infections, bacterial infections, viral infections.

3. Cutaneous manifestations of complications of diabetes mellitus eg. neuropathy, diabetic feet ulcer, pigmented purpura etc.
4. Skin reactions due to diabetic treatment - eg. lipoatrophy, lipohypertrophy, erythema multiforme, photosensitivity, urticaria, pruritus, lichenoid reaction.

\section{AIMS AND OBJECTIVES:}

The aim of this study is to study dermatological manifestations of diabetes mellitus.

\section{MATERIAL AND METHODS:}

This study was carried out on 200 patients of diabetes mellitus with cutaneous manifestations attending out-patient department of Dermatology at Jawahar Lal Nehru, Medical College, Ajmer. Inclusion criteria for study were patient with raised fasting or postprandial blood sugar level as per diagnostic criteria for diabetes mellitus adopted by American Diabetes Association 2019 and those require treatment for diabetes mellitus both type 1 and type $2^{10}$.Those with gestational diabetes were excluded from the study. A detailed history including age, sex, occupation socioeconomic status, clinical sign and symptoms, their duration, history of evolution and progression of lesion and its treatment, if any, were recorded. A thorough dermatological, general physical and systemic examination were done. All cutaneous and mucous lesions were recorded. Relevant laboratory investigation including complete blood count, blood sugar both fasting and postprandial, urine examination, liver and kidney function test, $\mathrm{HbAlc}$, lipid profile, fundus examination by an ophthalmologist, $\mathrm{KOH}$ examination, gram staining of pus in selected cases were done.

Assessment of diabetic neuropathy was done on basis of criteria detailed by foster. Relevant microbiological and histopathological examination were carried out in selected cases to confirm clinical diagnosis.

\section{RESULTS:}

During the study 200 patients of diabetes mellitus with cutaneous manifestations were observed and following information were recorded. The mean age of patient in this study is 52.48 years (ranges from 3.5-80 years). Out of 200 patients there were $57 \%$ (114) male and $43 \%$ (86) were female patients with slight male preponderance. Male: female ratio was 1.32:1. Among 200 patients $76 \%$ (152) were from urban areas and $24 \%$ (48) were from rural areas. Out of 200 patients $36.5 \%$ (73) patients had positive family history of diabetes mellitus and $127(63.5 \%)$ patients had no family history of 
diabetes. Among 200 patients blood sugar level was controlled i.e HbAlc $<7$ in $13 \%$ (26 patients) and was uncontrolled i.e. $\mathrm{HbAlc}>7$ in $87 \%$ (174) patients. Out of 200 patients $8 \%(16)$ patients were on insulin therapy and $92 \%$ (184) patients were on oral hypoglycemic drugs for control of their diabetes. Out of 200 patients $75.5 \%$ (151) patients had diabetes mellitus from $0-5$ year duration, $17 \%$ (34) patients had diabetes mellitus from 6-10 year duration, 7.5\% (15) patients had diabetes mellitus from more than 10 year duration.

Table - 1 Spectrum of diabetes associated cutaneous ma nifestations observed in study subjects.

\begin{tabular}{|l|l|}
\hline Skin disease & No. of patients (\%) \\
\hline Dermatophytic fungal infection & $23(11.5 \%)$ \\
\hline Candidal infection & $22(1 \%)$ \\
\hline Generalized pruritus & $21(10.5 \%)$ \\
\hline Acanthosis nigricans & $21(10.5)$ \\
\hline Skin Tags & $19(9.5 \%)$ \\
\hline Furunculosis (Boils) & $18(9 \%)$ \\
\hline Sclerosis of finger (finger pebbles) & $18(9 \%)$ \\
\hline Onychomycosis & $14(7 \%)$ \\
\hline Shin spot & $14(7 \%)$ \\
\hline Xanthelsma & $14(7 \%)$ \\
\hline Acquired icthyosis & $13(6.5 \%)$ \\
\hline Rubeosis faciei & $13(6.5 \%)$ \\
\hline Urticaria & $9(4.5 \%)$ \\
\hline Seborrheic keratosis & $9(4.5 \%)$ \\
\hline Periocular melanosis & $9(4.5 \%)$ \\
\hline Photodermatitis & $9(4.5 \%)$ \\
\hline Folliculitis & $8(4 \%)$ \\
\hline Scleredema diabeticorum & $8(4 \%)$ \\
\hline Melasma & $8(4 \%)$ \\
\hline $\begin{array}{l}\text { PIH (Post Inflammatory } \\
\text { Hyperpigmentation) }\end{array}$ & $8(4 \%)$ \\
\hline Limited joint mobility & $7(3.5 \%)$ \\
\hline Diabetic foot ulcer & $6(3 \%)$ \\
\hline Lichen amyloidosis & $5(2.5 \%)$ \\
\hline Carbuncle & $2(1 \%)$ \\
\hline Eruptive xanthoma & $2(1 \%)$ \\
\hline
\end{tabular}

\begin{tabular}{|l|l|}
\hline Lipohypertrophy & $1(0.5 \%)$ \\
\hline Diabetic bullae & $1(0.5 \%)$ \\
\hline
\end{tabular}

Among all type of cutaneous manifestations associated with diabetes mellitus, fungal infection was commonest association with $32.5 \%$ (65) cases followed by bacterial infection $21 \%$ (42).

\section{Table- 2 FUNGAL INFECTIONS ( $n=200$ )}

\begin{tabular}{|l|l|}
\hline Fungal infections & No. of patients (\%) \\
\hline Onychomycosis & $14(7 \%)$ \\
\hline Candidal balanoposthitis & $11(5.5 \%)$ \\
\hline Candidal vulvovaginitis & $4(2 \%)$ \\
\hline Candidal intertrigo & $4(2 \%)$ \\
\hline Tinea cruris & $11(5.5 \%)$ \\
\hline Tinea pedis & $6(3 \%)$ \\
\hline Tinea corporis & $6(3 \%)$ \\
\hline Pityriasis versicolor & $6(3 \%)$ \\
\hline Candidal paronychia & $3(1.5 \%)$ \\
\hline Total & $65(32.5 \%)$ \\
\hline
\end{tabular}

Among the all 200 patients there were 32.5(65) patients who had fungal infection of which most common was onychomycosis $7 \%$ (14), candidal balanoposthitis $5.5 \%$ (11) and least common was candidal paronychia in $1.5 \%$ (3) patients.

Table- 3 BACTERIAL INFECTIONS ( $n=200)$

\begin{tabular}{|l|l|}
\hline Bacterial infections & No. of patients (\%) \\
\hline Furunculosis & $18(9 \%)$ \\
\hline Folliculitis & $8(4 \%)$ \\
\hline Erythrasma & $5(2.5 \%)$ \\
\hline Bacterial interigo & $4(2 \%)$ \\
\hline Cellulitis & $3(1.5 \%)$ \\
\hline Carbuncle & $2(1 \%)$ \\
\hline Impetigo & $2(1 \%)$ \\
\hline Total & $42(21 \%)$ \\
\hline
\end{tabular}

Among all 200 patients most common bacterial infection was furunculosis comprising of $9 \%(18)$ cases and least common was carbuncle $1 \%$ (2) cases. Total $21 \%$ (42) cases were of bacterial infection.

Table-4 SPECIFIC DERIMATOSIS ASSOCIATED WITH DIABETES MELLITUS (n=200)

\begin{tabular}{|l|l|l|l|l|l|}
\hline Specific dermatosis & $\begin{array}{l}\text { Rubeosis } \\
\text { faciei }\end{array}$ & $\begin{array}{l}\text { Necrobiosis lipoidica } \\
\text { diabeticorum (NLD) }\end{array}$ & Granuloma annulare (G.A) & Lipohypertrophy & Total \\
\hline No.of patients & $13(6.5 \%)$ & $3(1.5 \%)$ & $4(2 \%)$ & $1(0.5 \%)$ & $21(10.5 \%)$ \\
\hline
\end{tabular}

\section{DISCUSSION:}

In our study there were $114(57 \%)$ males and $86(43 \%)$ females. There was slight male predominance. Some studies have shown slight male preponderance ${ }^{11}$ while others have shown female preponderance ${ }^{12}$. According to WHO excess male diabetics observed in South East Asia ${ }^{13}$. Age of patients in our study ranged from 35 years to 80 years with mean age of presentation being 52.48 years. Minimum duration of diabetes mellitus with cutaneous presentation was one month and maximum duration was 25 years with average being 4.15 years. Out of 200 patients, 151 patients $(75.5 \%)$ had diabetes mellitus of less than 5 year duration, 34 patients $(17 \%)$ had diabetes since 6 to 10 years and only 10 patients had diabetes for more than 10 years. It shows that diabetes mellitus can be fairly recognized or suspected with skin presentation alone. Alteras and Saryat ${ }^{14}$ and dogra et al ${ }^{15}$ also reported that in majority of patients with diabetes mellitus, cutaneous manifestations significantly correlated with duration of diabetes. In their study duration of disease was less than 6 years in majority of patients. Blood sugar level was uncontrolled ( $\mathrm{HbAlc}>7)$ in $87 \%$ (174) of patients, it was controlled $(\mathrm{HbAlc}<7)$, in only $13 \%$ (26) patients. As found by Yosipovitch G, et $\mathrm{al}^{16}$ and Sawhney et al ${ }^{17}$, skin manifestations were more common in patients who had uncontrolled diabetes. Uncontrolled diabetes increases risk of microan giopathy and other complications. Out of 200 patients $76 \%$ (152) patients were from urban background and $24 \%$ (48) were from rural background. This is in accordance with the fact that urban people with sedentary life style, specific dietary habits, lack of exercise and physical work and obesity are more prone to develop diabetes mellitus. Out of 200 patients $73(36.5 \%)$ had positive family history. This is testimonial to the fact that genetic factors do play a significant role in causation of this multi-factorial disease. Cutaneous infections were most common skin manifestations in our study being observed in $53.5 \%$ (107) patients, of which fungal infections were most prevalent being seen in $32.5 \%$ of cases, followed by bacterial infection in $21 \%$ cases. It was probably due to the fact that most of our patients belong to lower socioeconomic status residing in hot humid climatic condition, poor personal hygiene living in over crowded slums. Perez et $\mathrm{al}^{2}$ has shown that infections are most common cutaneous manifestations of diabetes mellitus. Other dermatosis associated with diabetes mellitus in our study were acanthosis nigricans $10.5 \%$ (21) cases, generalized pruritus $10.5 \%(21)$ cases, skin tags in $9.5 \%$ (19) cases, finger pebbles in $9 \%$ (18) cases, skin spots in $7 \%$ (14) cases, acquired icthyosis $6.5 \%$ (13) cases, rubeosis faciei $6.5 \%$ (13) cases, xanthelesma 7\% (14) cases, telogen effluvium 5\% (10) cases. Diabetic foot ulcers due to neuropathy and microangiopathy 
were present in 3\% (6) cases. Specific dermatosis have shown association with diabetes mellitus in many studies like diabetic bullae, necrobiosis lipoidica, granuloma annulare. The above specific dermatosis were also present in our study respectively in $0.51 \%$ (1) case, $1.5 \%$ (3) $2 \%$ (4) cases. Similar results have been shown by Tariq Mahmood et $\mathrm{al}^{18}$ and Braverman $\mathrm{IM}^{19}$. These specific dermatosis were present in our study at frequency similar to other studies like Pandey et $\mathrm{al}^{20}$. Amongst 200 patients few cases due to complications of therapy were also observed. Lipohypertrophy at injection site due to insulin was present in one case $0.5 \%$ (1) case, erythema multiforme like skin rash due to oral hypoglycemic drugs was seen in $0.5 \%$ (1) case. Few cases of photodermatitis like rash were also observed.

\section{CONCLUSION:}

Thus, a variety of cutaneous manifestations in diabetes mellitus have been observed in our study which helps to diagnose diabetes merely by careful inspection of skin. Skin manifestation of diabetes mellitus generally appear after systemic disease has developed but in few cases may predate or even appear concurrently with it.

FUNDING : No funding source

\section{CONFLICT OF INTEREST: None declared}

\section{ETHICAL APPROVAL :}

The study was approved by the institutional ethical committee.

\section{REFERENCES}

1. Jennifer, John E. Diabetes mellitus In : Irvin MF, Arthur Z, Klaus W, Austen KF Goldsmith LA, Katz SI, editors. Dermatology in General Medicine 6th Ed. McGraw Hill. Medical Publishing Division :New York;2003,P. 1651-61.

2. Perez MI, Kohn SR. Cutaneous manifestations of diabetes mellitus.J Am Acad Dermatol 1994;30:519-31.

3. Wahid Z, Kanjee A. Cutaneous manifestations of diabetes mellitus. J Pak Med Assoc 1998;48:304-5.

4. Paron NG, Lambert PW. Cutaneous manifestations of diabetes mellitus. Prim Care 2000;27:371-83.

5. Romano G, Moretti G, Di Benedetto et al. Skin lesions in diabetes mellitus: prevalence and clinical correlations. Diabetes Res Clin Pract 1998;39:101-6.

6. Buckingham BA et al. Scleroderma like changes in insulin-dependent diabetes mellitus: Clinical and biochemical studies. Diabetes Care 7:163,1984.

7. Olerud JE: Ellenburg and Rifkin's Diabetes Mellitus. New York, McGraw-Hill, 895-908, 2003.

8. Cruz PD Jr, Hud JA Jr: Excess insulin binding to insulin like growth factor receptor: Proposed mechanism for acanthosis nigricans. J Invest Dermatol 98:825, 1992.

9. Ansel JC et al:Interactions of the skin and nervous system.J Investig Dermatol Symp Proc 2:23,1997.

10. American Diabetes Association. Diabetes care 2019 Jan;42 (supplement): S13-S28

11. Goyal A, Raina S, Mahajan V, Sharma NL. Cutaneous manifestation of diabetes mellitus. Indian JDermatol 2010;55(1):39-41

12. BhatYJ, Gupta V, Kudyar RP. Cutaneous manifestation of diabetes mellitus. Int $J$ Diab Ctries 2006;26:152-5.

13. WHO (1980).Tech.Rep.Ser.No.646.

14. Alteras I, Saryt E. Prevalence of pathogenic fungi in the toe webs and the nail of diabetes patients. Mycopathologia 1979;67:157-9.

15. Dogra S, Kumar B, Bhansali A, Chakrabarty A. Epedemiology of onychomycosis in patients with diabetes mellitus in India. Int J Dermatol 2002;41:647-51.

16. Yosipovitch G, Hodak E, Vardi P, Shraga I, Karp M, Sprecher E. et al. The prevalence of cutaneous manifestation in IDDM patients and their association with diabetes risk factors and microvascular complication. Diabetes care 1998;21:506-9.

17. Sawhney MP, Tutakne MP, Rajpathak SD. Clinical study of diabetic angiopathy. Indian JDermatolVenerol Leprol 1996;56:18-21.

18. Mahmood T, UI-Bari A, Agha H. Cutaneous manifestation of diabetes mellitus. JPak Assoc Dermatol 2005; 15:227-32.

19. Braverman IM. Cutaneous manifestation of diabetes mellitus. Med Clin North Am 1971;55:1019-29.

20. Nigam PK, Pande S. Pattern of dermatosis in diabetes. Indian J Dermatol Venerol Leprol 2003;69:83-5 